\title{
Accuracy of three electronic apex locators in the presence of different irrigating solutions
}

\section{Ana Laura Pion Carvalho(a) Cacio Moura-Netto(b) \\ Abilio Albuquerque Maranhão de Moura ${ }^{(b)}$ \\ Márcia Martins Marques ${ }^{(b)}$ Harry Davidowicz ${ }^{(a)}$}

(a) Department of Endodontics, Universidade Paulista, São Paulo, SP, Brazil

(b) Department of Endodontics, Universidade de São Paulo (USP), São Paulo, SP, Brazil

\section{Corresponding author:}

Cacio Moura-Netto

R. Prof. Lineu Prestes, 2227 - Depto

de Dentistica

Cidade Universitária

São Paulo - SP - Brasil

CEP: 05508-000

E-mail:caciomn@usp.br

Received for publication on May 25, 2010 Accepted for publication on Aug 27, 2010

\begin{abstract}
The present study compared the accuracy of three electronic apex locators (EALs) - Elements Diagnostic ${ }^{\circledR}$, Root ZX ${ }^{\circledR}$ and Apex DSP ${ }^{\circledR}$ - in the presence of different irrigating solutions $(0.9 \%$ saline solution and $1 \%$ sodium hypochlorite). The electronic measurements were carried out by three examiners, using twenty extracted human permanent maxillary central incisors. A size $10 \mathrm{~K}$ file was introduced into the root canals until reaching the 0.0 mark, and was subsequently retracted to the 1.0 mark. The gold standard (GS) measurement was obtained by combining visual and radiographic methods, and was set $1 \mathrm{~mm}$ short of the apical foramen. Electronic length values closer to the GS $( \pm 0.5 \mathrm{~mm})$ were considered as accurate measures. Intraclass correlation coefficients (ICCs) were used to verify inter-examiner agreement. The comparison among the EALs was performed using the McNemar and Kruskal-Wallis tests $(\mathrm{p}<0.05)$. The ICCs were generally high, ranging from 0.8859 to 0.9657 . Similar results were observed for the percentage of electronic measurements closer to the GS obtained with the Elements Diagnostic ${ }^{\circledR}$ and the Root $\mathrm{ZX}^{\circledast}$ EALs ( $\left.\mathrm{p}>0.05\right)$, independent of the irrigating solutions used. The measurements taken with these two EALs were more accurate than those taken with Apex DSP ${ }^{\circledR}$, regardless of the irrigating solution used $(\mathrm{p}<0.05)$. It was concluded that Elements Diagnostic ${ }^{\circledR}$ and Root $\mathrm{ZX}^{\circledR}$ apex locators are able to locate the cementum-dentine junction more precisely than Apex DSP ${ }^{\circledR}$. The presence of irrigating solutions does not interfere with the performance of the EALs.
\end{abstract}

Descriptors: Dental Instruments; Odontometry; Root Canal Therapy; Endodontics.

\section{Introduction}

Correct determination of working length is a key factor that can influence the outcome of root canal treatment. ${ }^{1-5}$

The cementum-dentine junction (CDJ) is thought of as the ideal limit for endodontic instrumentation because of the small diameter of the root canal at that point. Moreover, it has been established that endodontic procedures should take place inside the root canal and should not affect the cementum, thereby preserving the remaining apical periodontal tissue..$^{6-9}$

Establishing the exact limit of the CDJ is not simple, as shown in the classic study by Kuttler. ${ }^{10}$ Using 268 extracted teeth, it was observed that 
the distance between the CDJ and the apical foramen varied from 0.5 to $0.6 \mathrm{~mm}$. In addition, studies have concluded that the location of the apical foramen is also variable, usually $0.3-3.80 \mathrm{~mm}$ distal to the anatomic apex of the tooth root. ${ }^{11-13}$ The use of radiographs is associated with several limitations, such as exposure of patients to radiation, difficulties in image interpretation due to the superpositioning of anatomic structures, and the frequent impossibility of determining the exact location of the CDJ or apical foramen. ${ }^{14-15}$

The use of electronic apex locators (EALs) in clinical practice is well established, and several studies have compared the results obtained from different models of EALs to others obtained from radiographic findings. ${ }^{1,3-4,7,11}$

On the other hand, few studies have focused on the influence of different irrigating solutions used along with such devices. ${ }^{16-17}$ Therefore, the objective of this laboratory study was to compare the accuracy of three different EALs (Elements Diagnostic ${ }^{\circledR}$, Root $\mathrm{ZX}^{\circledR}$ and Apex DSP ${ }^{\circledR}$ ) in the presence of two irrigating solutions $(0.9 \%$ saline solution and $1 \%$ sodium hypochlorite).

\section{Materials and Methods Sample selection and preparation}

The study was approved by the Research Ethics Committee of the School of Dentistry at Universidade Paulista, São Paulo, Brazil. Twenty extracted human permanent maxillary central incisors were randomly selected from the tooth bank of the School of Dentistry at Universidade Paulista. Specimens were immersed in $10 \%$ formalin for $48 \mathrm{~h}$, and then washed with $1 \%$ sodium hypochlorite and brushed under running water. Teeth were placed in labeled vials containing saline solution, numbered 1 to 20 , and stored at $37^{\circ} \mathrm{C}$ for $72 \mathrm{~h}$.

\section{Gold standard root canal length}

The Gold standard (GS) measurement of root canal length was carried out using a visual method followed by buccolingual radiographs to assess the position of the file within the working length of the root canal. Aided by the use of an operative microscope under 10 magnification, a size $10 \mathrm{~K}$ file was inserted into each canal until the tip became visible at the major apical foramen and a rubber stop was then positioned at the coronal reference point. The working length was then established as $1.0 \mathrm{~mm}$ shorter than the measured distance. The teeth were radiographed again and the measurements were reconfirmed.

\section{Examination methods}

Subsequently, teeth were fixed in a sponge, soaked in $0.9 \%$ saline solution at $37^{\circ} \mathrm{C}$, in a plastic container. Canals were filled with $0.9 \%$ saline solution and electronic measurements were taken using the following EALs: Elements Diagnostic ${ }^{\circledR}$ (SybronEndo, Redmond, WA, USA), Root ZX ${ }^{\circledR}$ (J. Morita, Tokyo, Japan) and Apex DSP ${ }^{\circledR}$ (Septodont, Saint Maur, France).

After reaching the 0.0 mark on the display, the file was retracted to the 1.0 mark on the display and the measurement was recorded in millimeters. Three different examiners carried out this procedure for electronic measurements with each EAL. The mean of the three measurements was used for the statistical analysis. After one week, $0.9 \%$ saline solution was replaced by $1 \%$ sodium hypochlorite and measurements were repeated.

\section{Statistical analysis}

Measurement agreements between examiners were calculated for each method, using the actual values of the devices, by intraclass correlation coefficient (ICC) analysis. Then, the gold standard value was subtracted from the distance determined by each method. Values closer to the gold standard $( \pm 0.5 \mathrm{~mm})$ were considered as acceptable measures. Negative values, less than $0.5 \mathrm{~mm}$, were classified as shorter than the GS; positive values, greater than $0.5 \mathrm{~mm}$, were categorized as longer than the GS. Measurements shorter or longer than the GS were collapsed and the analyses were performed comparing the methods in pairs, using the McNemar test (different EALs in the same solution, and each EAL in different solutions).

Comparisons among the methods were also performed using absolute differences. As the differences were not normally distributed (Kolmogorov- 
Smirnov test), the comparisons were carried out using Kruskal-Wallis test. All analyses were performed using BioEstat 4.0 statistical software (Manuel Ayres, Pará, Brazil) and the level of significance for all tests was $\mathrm{P}<0.05$.

\section{Results}

The intraclass correlation coefficient (ICC) analysis showed high levels of agreement between examiners for all methods, ranging from 0.8859 to 0.9657.

The distributions and the percentages of shorter than, closer to, or longer than the gold standard measurements are presented in Table 1.

Independent of the irrigating solutions used ( $0.9 \%$ saline solution and $1 \%$ sodium hypochlorite), the majority of measurements taken with the Elements Diagnostic ${ }^{\circledast}$ and Root ZX ${ }^{\circledast}$ EALs were closer to those of the gold standard, whereas the majority of measurements taken with the Apex DSP ${ }^{\circledR} \mathrm{EAL}$ were shorter than those of the gold standard.

For both irrigating solutions used, the mean of the absolute differences from the gold standard obtained with the Apex DSP ${ }^{\circledR}$ were significantly higher than those obtained with the other two EALs used (Table 2).

\section{Discussion}

As pointed out by several authors, the apical region may present important anatomic variations which make it difficult to locate the CDJ and the apical foramen. ${ }^{10-13}$ Determination of the apical foramen location, or working length analysis, has traditionally been performed using radiographic methods. However, because of the limitations associated with image interpretation in such methods, the use of electronic apex locators has become increasingly prevalent in clinical practice. ${ }^{16,18-20}$ Nevertheless, studies have shown differences in the accuracy of EALs. ${ }^{6,8,16,19-20}$ Thus, in order to compare the accu-

Table 1 - Distribution and percentage of electronic measurements: shorter than, closer to and longer than those obtained using the gold standard method.

\begin{tabular}{|c|c|c|c|c|c|c|}
\hline \multirow{2}{*}{\multicolumn{2}{|c|}{ Method }} & \multirow{3}{*}{$\begin{array}{c}\text { Shorter than GS } \\
(<0.5 \mathrm{~mm})(\%) \\
7(35)\end{array}$} & \multirow{3}{*}{$\begin{array}{c}\text { Closer to GS } \\
( \pm 0.5 \mathrm{~mm})(\%) \\
10(50)\end{array}$} & \multirow{3}{*}{$\begin{array}{c}\text { Longer than GS } \\
\begin{array}{c}(>0.5 \mathrm{~mm})(\%) \\
3(15)\end{array}\end{array}$} & \multicolumn{2}{|c|}{ McNemar test* } \\
\hline & & & & & \multirow{2}{*}{$\begin{array}{c}\text { vs. EAL } \\
\text { A }\end{array}$} & \multirow{2}{*}{$\begin{array}{c}\text { vs. irrigating solution } \\
\text { n.s. }\end{array}$} \\
\hline \multirow{3}{*}{$\begin{array}{l}0.9 \% \\
\text { saline } \\
\text { solution }\end{array}$} & Elements Diagnostic & & & & & \\
\hline & Root ZX & $1(5)$ & $17(85)$ & $2(10)$ & $A$ & n.s. \\
\hline & Apex DSP & $16(80)$ & $4(20)$ & $0(0)$ & B & n.s. \\
\hline \multirow{3}{*}{$\begin{array}{l}1 \% \\
\mathrm{NaOCl} \\
\text { solution }\end{array}$} & Elements Diagnostic & $2(10)$ & $15(75)$ & $3(15)$ & A & n.s. \\
\hline & Root ZX & $1(5)$ & $16(80)$ & $3(15)$ & $A$ & n.s. \\
\hline & Apex DSP & $16(80)$ & $3(15)$ & $1(5)$ & B & n.s. \\
\hline
\end{tabular}

*Significance obtained through McNemar test comparing the methods in pairs. Different letters indicate statistically significant differences among the EALs $(\mathrm{P}<0.05)$.

Table 2 - Mean and standard deviation (SD) values of the absolute differences observed between the GS length and the measurements obtained with the different electronic methods of root canal length measurement.

\begin{tabular}{|c|c|c|c|c|c|}
\hline & \multirow{2}{*}{ Irrigants/EALs } & \multicolumn{2}{|c|}{ Absolute difference } & \multicolumn{2}{|c|}{ Kruskal-Wallis test * } \\
\hline & & Mean & SD & vs. EAL & vs. irrigating solution \\
\hline \multirow{3}{*}{$\begin{array}{l}0.9 \% \\
\text { saline } \\
\text { solution }\end{array}$} & Elements Diagnostic $^{\circledR}$ & 0.57 & 0.39 & A & n.s. \\
\hline & Root ZX ${ }^{\circledR}$ & 0.33 & 0.34 & A & n.s. \\
\hline & Apex DSP ${ }^{\circledR}$ & 1.15 & 0.80 & B & n.s. \\
\hline \multirow{3}{*}{$\begin{array}{l}1 \% \\
\mathrm{NaOCl} \\
\text { solution }\end{array}$} & Elements Diagnostic ${ }^{\circledR}$ & 0.53 & 0.55 & A & n.s. \\
\hline & Root ZX ${ }^{\circledR}$ & 0.37 & 0.29 & A & n.s. \\
\hline & Apex DSP ${ }^{\circledR}$ & 1.30 & 0.90 & B & n.s. \\
\hline
\end{tabular}

*Significance obtained through Kruskal-Wallis test. Different letters indicate statistically significant differences among the EALs $(P<0.05)$. 
racy of three currently used electronic apex locators, Root ZX ${ }^{\circledR}$, Elements Diagnostic ${ }^{\circledR}$, and Apex DSP ${ }^{\circledR}$, this study was performed using human, single-rooted teeth.

There are various ways to try to reproduce in vivo conditions. Some authors use an alginate model or gelatin, others use a sponge soaked in a solution chosen by the authors. ${ }^{21-22}$ In the present study, the in vitro model employed aimed to reproduce in vivo conditions using a sponge soaked in saline solution. Saline solution has properties similar to those of alveolar bone and its fluids, according to well-established protocols. ${ }^{16}$ Regarding the irrigating solutions, manufacturers have provided information that the presence of fluids or irrigating solutions such as sodium hypochlorite does not interfere with the accuracy of the devices. In fact, this finding was confirmed in this study because the irrigating solutions did not interfere with the results obtained with any of the EALs used. Jenkins et al. ${ }^{18}$ achieved similar results testing Root $\mathrm{ZX}^{\circledR}$ in different solutions, as did Kang and $\mathrm{Kim}^{17}$ comparing different EALs under various conditions.

Using the visual and radiographic methods as the gold standard for locating the CDJ, we have shown that the data obtained with Elements Diagnostic ${ }^{\circledR}$ and Root $\mathrm{ZX}^{\circledR}$ locators were more accurate than those of Apex DSP ${ }^{\circledR}$, independent of the irrigating solution. In fact, most of the measurements

\section{References}

1. Pallares A, Faus V. An in vivo comparative study of two apex locators. J Endod. 1994 Dec;20(12):576-9.

2. Nguyen HO, Kaufman AY, Komorowski RC, Friedman S. Electronic length measurement using small and large files in enlarged canals. Int Endod J. 1996 Nov;29(6):359-64.

3. Nekoofar MH, Ghandi MM, Hayes SJ, Dummer PM. The fundamental operating principles of electronic root canal length measurement devices. Int Endod J. 2006 Aug;39(8):595-609.

4. Plotino G, Grande NM, Brigante L, Lesti B, Somma F. Ex vivo accuracy of three electronic apex locators: Root ZX, Elements Diagnostic Unit, Apex Locator and ProPex. Int Endod J. 2006 May;39(5):408-14.

5. ElAyouti A, Dima E, Ohmer J, Sperl K, von Ohle C, Löst C. Consistency of apex locator function: a clinical study. J Endod. 2009 Feb;35(2):179-81. obtained with Elements Diagnostic ${ }^{\circledR}$ and Root ZX ${ }^{\circledR}$ locators were closer to the GS measurements.

Many studies on the performance of the Elements Diagnostic ${ }^{\circledR}$ and Root ZX ${ }^{\circledR}$ EALs have shown high percentages of measurements close to those of the gold standards, with no significant differences between these two EALs. ${ }^{4,8,19,23-24}$ In other studies, the high accuracy of the Root $\mathrm{ZX}^{\circledR}$ was confirmed. ${ }^{6,16,20}$ Moreover, the Apex DSP ${ }^{\circledR}$ showed low accuracy in a recent study by de Camargo et al. ${ }^{24}$ in which the authors measured the accuracy of this EAL in function of the preflaring of root canals. These findings are consistent with our study in pointing out the importance of choosing the best possible EAL system, as different devices give measurements with different levels of accuracy.

\section{Conclusions}

Within the limitations of this in vitro study, we concluded that Elements Diagnostic ${ }^{\circledR}$ and Root ZX ${ }^{\circledR}$ apex locators were able to locate the cementumdentine junction more precisely than Apex DSP $^{\circledR}$. Moreover, the presence of irrigating solutions does not interfere with the performance of the EALs.

\section{Acknowledgments}

We would like to thank Prof. Dr. Fausto Medeiros Mendes (Universidade de São Paulo) for his support with statistical analysis.

6. Hassanien EE, Hashem A, Chalfin H. Histomorphometric study of the root apex of mandibular premolar teeth: an attempt to correlate working length measured with electronic and radiograph methods to various anatomic position in the apical portion of the canal. J Endod. 2008 Apr;34(4):408-12.

7. Venturi M, Breschi L. A comparison between two electronic apex locators: an in vivo investigation. Int Endod J. 2005 Jan;38(1):36-45.

8. Brisenõ-Marroquín B, Frajlich S, Goldberg F, Willershausen B. Influence of instrument size on the accuracy of different apex locators: an in vitro study. J Endod. 2008 Jun;34(6):698702 .

9. Siu C, Marshall JG, Baumgartner JC. An in vivo comparison of the Root ZX II, the Apex NRG XFR, and Mini Apex Locator by using rotary nickel-titanium files. J Endod. 2009 Jul;35(7):962-5. 
10. Kuttler Y. Microscopic investigation of root apexes. J Am Dent Assoc. 1955 May;50(5):544-52.

11. Gutierrez JH, Aguayo P. Apical foraminal openings in human teeth (number and location). Oral Surg Oral Med Oral Pathol Oral Radiol Endod. 1995 Jun;79(6):769-77.

12. Green D. Stereomicroscopic study of 700 root apices of maxillary and mandibular posterior teeth. Oral Surg Oral Med Oral Pathol. 1960 Jun;13(6):728-33.

13. Burch JG, Hulen S. The relationship of the apical foramen to the anatomic apex of the tooth root. Oral Surg Oral Med Oral Pathol. 1972 Aug;34(2):262-8.

14. Lucena-Martin C, Robles-Gijon V, Ferrer-Luque CM, de Mondelo JM. In vitro evaluation of the accuracy of three electronic apex locators. J Endod. 2004 Apr;30(4):231-3.

15. ElAyouti A, Kimionis I, Chu AL, Lost C. Determining the apical terminus of root-end resected teeth using three modern apex locators: a comparative ex vivo study. Int Endod J. 2005 Nov;38(11):827-33.

16. Goldberg F, Marroquin BB, Frajlich S, Dreyer C. In vitro evaluation of the ability of three apex locators to determine the working length during retreatment. J Endod. 2005 Sep;31(9):676-8.

17. Kang JA, Kim SK. Accuracies of seven different apex locators under various conditions. Oral Surg Oral Med Oral Pathol Oral Radiol Endod. 2008 Oct;106(4):e57-62.
18. Jenkins JA, Walker WA $3^{\text {rd }}$; Schindler WG, Flores CM. An in vitro evaluation of the accuracy of the Root $\mathrm{ZX}$ in the presence of various irrigants. J Endod. 2001 Mar;27(3):209-11.

19. Tselnik M, Baumgartner JC, Marshall JG. An evaluation of Root ZX and Elements Diagnostic Apex Locators. J Endod. $2005 \mathrm{Jul} ; 31(7): 507-9$.

20. D’Assunção FL, Albuquerque DS, Ferreira LC. The ability of two apex locators to locate the apical foramen: an in vitro study. J Endod. 2006 Jun;32(6):560-2.

21. Pascon EA, Marrelli M, Congi O, Ciancio R, Miceli F, Versiani MA. An ex vivo comparison of working length determination by 3 electronic apex locators. Oral Surg Oral Med Oral Pathol Oral Radiol Endod. 2009 Sep;108(3):e147-51.

22. Guise GM, Goodell GG, Imamura GM. In vitro comparison of three electronic apex locators. J Endod. 2010 Feb;36(2):27981.

23. Bernardes RA, Duarte MA, Vasconcelos BC, Moraes IG, Bernardineli N, Garcia RB, et al. Evaluation of precision of length determination with 3 electronic apex locators: Root ZX, Elements Diagnostic Unit and Apex Locator, and RomiAPEX D-30. Oral Surg Oral Med Oral Pathol Oral Radiol Endod. 2007 Oct;104(4):e91-4.

24. de Camargo EJ, Zapata RO, Medeiros PL, Bramante CM, Bernardineli N, Garcia RB, et al. Influence of preflaring on the accuracy of length determination with four electronic apex locators. J Endod. 2009 Sep;35(9):1300-2. 